\title{
ANÁLISE DE JOGO NOS JOGOS ESPORTIVOS COLETIVOS: A EXEMPLO DO VOLEIBOL
}

\author{
Cristino Júlio Alves da Silva Matias \\ Universidade Federal de Minas Gerais, Belo Horizonte, Minas Gerais, Brasil.
}

\section{Pablo Juan Greco}

Universidade Federal de Minas Gerais, Belo Horizonte, Minas Gerais, Brasil.

\begin{abstract}
Resumo
Os Jogos Esportivos Coletivos, desde 1930, são estudados nas Ciências do Esporte e pelas próprias comissões técnicas por meio de instrumentos de análise de jogo, para maior compreensão da lógica dos jogos. Este artigo visa apresentar a aplicação e os recursos tecnológicos para análise de jogo. Além disto, apresenta a análise de jogo exemplificada na modalidade esportiva Voleibol, mediante a evolução tática e a sua prática em alto nível no desporto atual. No jogo de Voleibol há sempre seis diferentes times em quadra, combinando com seis diferentes times do adversário, com combinações dependendo da fase de jogo, configurando de tal modo a importância da análise de jogo no Voleibol.
\end{abstract}

Palavras-chave: Análise de Jogo - Jogos Esportivos Coletivos - Voleibol.

\section{Introdução}

$\mathrm{O}$ estudo do jogo a partir da observação do comportamento dos jogadores nas modalidades esportivas coletivas iniciou-se nos Estados Unidos em 1931 com Messermith e Corey que pesquisavam distâncias percorridas em jogo pelos atletas de basketball. Atualmente, os estudos centram-se no comportamento tático dos atletas, descrito na literatura com os termos: observação de jogo (game observation), análise de jogo (match analysis; analysis of the game), estatística de jogo (scout) e análise notacional (notational analysis). A denominação "análise de jogo" é a mais empregada na literatura, considera-se neste conceito o englobamento da observação dos eventos táticos no transcorrer do jogo, do registro dessa observação e da interpretação desses inúmeros registros ou banco de dados (GARGANTA, 2001).

A análise de jogo é considerada primordial no treino e na competição, pois fornece informações a respeito do efeito das tomadas de decisões dos atletas. Pela apreciação dessas informações é possível o aprimoramento da eficácia do atleta, dos seus processos decisórios, bem como o planejamento e o controle dos treinamentos. Além disso, pode-se testar e/ou treinar os sistemas de ataque e defesa para avaliar a perspectiva de rendimento positivo de cada um dos atletas e da equipe como um todo (BAACKE; MATSUDAIRA, 1978; LERBARCH; LIMA, 1998; HUGHES; BARTLLET, 2002; LIEBERMANN et al., 2002; RUANO; GALVO, 2007). Garganta (2001, p. 57) refere-se à importância da análise de jogo: 
[...] o conhecimento acerca da proficiência com que os jogadores e as equipes realizam as diferentes tarefas tem-se revelado fundamental para aferir a congruência da sua prestação em relação aos modelos de jogo e de treino preconizados.

No processo de treinamento e competição muitos testes de laboratório e de campo sempre estiveram disponíveis para avaliação física dos atletas, já a tomada de decisão tática, via execução de uma habilidade motora, sempre foi avaliada pelos treinadores por meio da utilização de critérios subjetivos (NETO, 2007), embora seja a avaliação geral do treinador muito importante (ARAÚJO; VOLOSSOVITCH, 2005; NETO, 2007). Com o advento da evolução tecnológica do século XX, que disponibilizou o uso de videoteipes e de recursos de informática (VILHENA, 2007), passou-se a avaliar de modo mais estruturado e objetivo o resultado do processo da tomada de decisão para elaboração de planos táticos ou estratégicos 1 , principalmente a partir dos anos 80 (PEREIRA; MESQUITA, 2004; GARGANTA, 2001; LIEBERMANN et al., 2002). Deste modo, as comissões técnicas trabalham na elaboração de treinamentos para maximizar as qualidades decisórias dos jogadores, aprimorar as ações de baixa eficácia e, por conseguinte, se adaptar especificamente a cada adversário (LERBARCH; LIMA, 1998; RUANO; CALVO, 2007; SZWARC, 2008). Os mesmos recursos são de valor na condução tática das equipes durante as partidas, por meio da informação do rendimento individual dos atletas da própria equipe e dos adversários, por consequência se dando elaborações e adaptações de novos planos táticos (LERBARCH; LIMA, 1998; MORENO, 2003; MATIAS et al., 2005; NETO, 2007; SZWARC, 2008).

\section{Aplicação da análise de jogo}

A análise de jogo tem sido utilizada cada vez mais por equipes esportivas, tal aplicação se averigua também na pesquisa científica dentro das Ciências do Esporte (GARGANTA, 2001; PONCE; ORTEGA, 2003). Os estudiosos das diferentes modalidades esportivas têm procurado compreender a diferença de performance dos jogadores e das equipes, com o objetivo de identificar os fatores que determinam significativamente o resultado da eficácia das ações táticas individuais, de grupo e coletivas (ANGUERA, 2000; GARGANTA tática individual diz respeito à ação de um jogador, que, por meio da aplicação de uma técnica, visa atingir um determinado objetivo. Pode ser exemplificada na busca do ponto direto na execução do saque no voleibol. A tática de grupo pode ser evidenciada nas ações entre dois ou três jogadores, por intermédio da realização de uma sequência de técnicas individuais, que visa um objetivo comum. No voleibol, pode ser explicitada por elementos táticos da ação de bloqueio, que preenche um determinado espaço da trajetória da linha de ataque adversária e o defensor, que preenche o outro espaço e/ou linha da bola a ser atacada. Já a tática coletiva se relaciona com as ações que envolvam mais de três jogadores, realizadas a partir de um plano geral pré-estabelecido, no intuito de alcançar o objetivo desejado. No voleibol esta situação ocorre quando a defesa e o bloqueio se movimentam de acordo com o resultado do saque da própria equipe, o sistema defensivo inicia-se no saque e já se movimenta no primeiro toque na bola efetuado pelo adversário (GRECO; CHAGAS, 1992; GRECO; BENDA, 1998).A, 2001; MORENO, 2003; COLEMAN, 2005). 
Deste modo, a análise da performance tática tem possibilitado:

- configurar modelos da atividade dos jogadores e das equipes;

- promover o desenvolvimento de métodos de treino que garantam maior especificidade e, portanto, superior transferibilidade para o jogo;

- indicar tendências evolutivas das diferentes modalidades esportivas.

A tecnologia da informação disponível para o aprimoramento dos atletas e conquistas de vitórias e campeonatos não é aproveitada por alguns treinadores conservadores que não fazem uso da análise de jogo, pois consideram que as suas experiências são suficientes para interpretar e avaliar o processo tático inerente aos treinamentos e competições (GARGANTA, 2001). No estudo de Franks e McGarry (1996), os treinadores de futebol, experientes e novatos, foram indagados sobre os acontecimentos ocorridos após 45 minutos de uma partida de futebol. Os treinadores experientes demonstraram um índice de acerto mais baixo que os novatos, além disso se comportaram de forma confiante, mesmo com respostas com conteúdo errado. No estudo de Wnorowski (2007), os treinadores peritos não souberam descrever todas as situações ocorridas em uma partida de voleibol, apesar de descreverem corretamente a eficácia de cada um dos seis fundamentos. Assim, é impossível relembrar todos os acontecimentos que ocorrem no transcorrer de uma partida e, menos ainda, as inúmeras ocorrências táticas efetuadas por cada um dos atletas (com ou sem posse da bola) e da equipe como um todo, ao longo de um jogo, ou de vários jogos de um ou mais campeonatos (FRANK; McGARRY, 1996; GARGANTA, 2001; WNOROWSKI, 2007).

Para a análise de jogo, há hoje inúmeros hardwares e softwares que permitem a criação de banco de dados, sendo "papel e lápis" um recurso obsoleto. Estas ferramentas tecnológicas atuais auxiliam na melhor compreensão das modalidades esportivas, via registro de dados com um número maior de itens a serem observados e analisados. Além disso, dados são acessados de forma rápida. É possível, dentro do banco de dados, cruzar categorias de cada um dos itens com categoria pré-selecionadas de outra categoria, isso se denomina "aplicação de filtro". Por exemplo, optar em averiguar dentro da categoria "posição" o item levantador na posição de rodízio número um; na categoria "recepção" o item passe em que a bola chegou para o levantador na zona de ataque dois ou três. O resultado desse filtro poderá ser mostrado, em cada uma das categorias, em bloco de semelhanças de itens, pelo somatório de cada item idêntico e em concomitância com outras categorias que foram filtradas ou não, tal como o "resultado do ataque", com os itens ponto, erro e continuação, e "estado do bloqueio", com os itens simples, duplo ou triplo (GARGANTA, 2001; LIEBERMANN et al., 2002; MATIAS et al., 2005).

\section{Recursos tecnológicos para análise de jogo}

Os recursos atuais permitem a análise de jogo mediante o registro in loco da partida ou treino, por meio de uma grelha ou lista de atributos, que será composta por categorias pré-determinadas ou categorias construídas e inseridas no software, Data Project e Simi Scout (Figura 1), respectivamente (MATIAS et al., 
2005; MORTENSEN, 2007). O filtro desses programas de computador permite a combinação da ação selecionada, seja uma ou mais categorias combinadas, com a calibração do tempo da imagem em vídeo do respectivo registro da ação. Assim, ao se efetuar o estudo do jogo será possível perceber toda movimentação tática individual, de grupo ou coletiva efetuada, pois poderá ser determinado o tempo de visualização antes e após o registro da ação, como cinco segundos antes e três depois, para se averiguar todo o contexto que compõe a tomada de decisão. Ao filtrar as categorias e calibrar o tempo de registro da imagem, será possível perceber outras variáveis integrantes do contexto da decisão, seja pela imagem real, pela reconstrução geométrica do registro da ação na quadra ou campo da modalidade, estatística descritiva e gráficos desta. Desse modo, não existe a limitação do "lápis e papel" ou softwares que fazem apenas o registro simples da tomada de decisão, tal como erro ou acerto em uma determinada jogada, que impossibilita melhor análise da pessoa, do ambiente e da tarefa (LIEBERMANN et al., 2002; MATIAS et al., 2005; ZAMBERLAM, 2005; MORTENSEN, 2007).

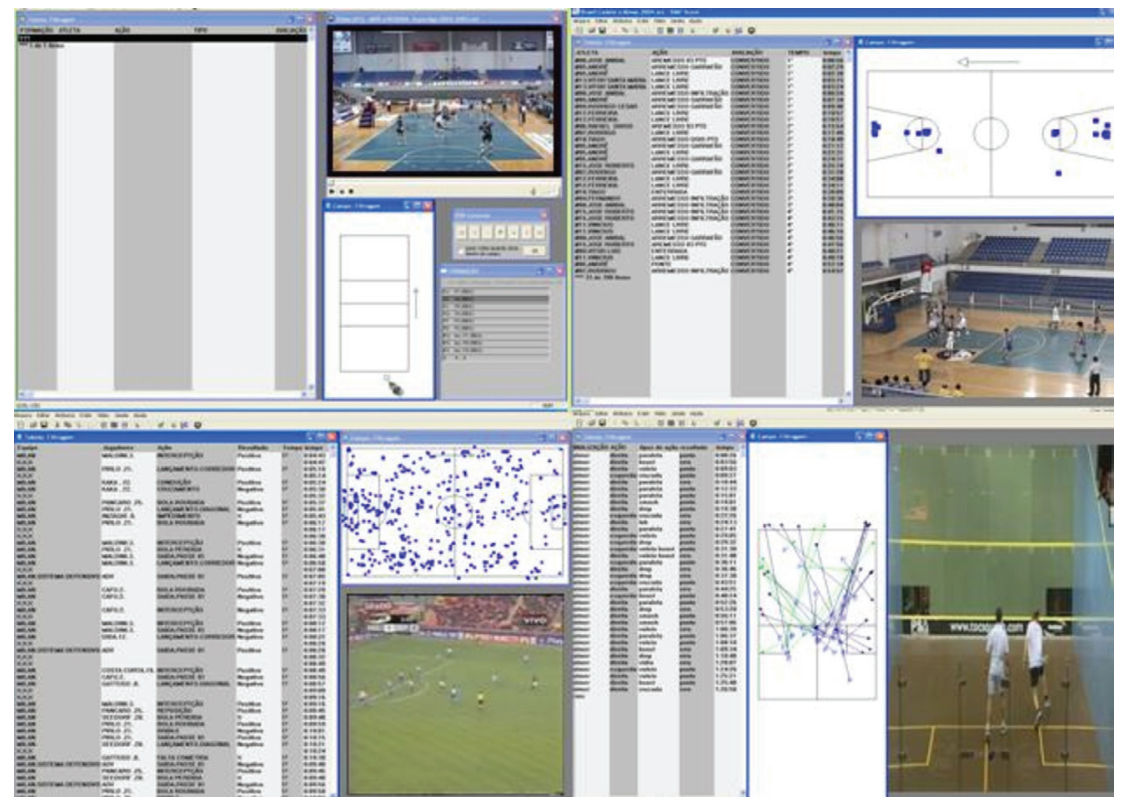

Figura 1 - Software de análise de jogo Simi Scout.(MATIAS et al., 2005b).

A construção do banco de dados na análise de jogo deve ser realizada por pessoas que tenham a compreensão da modalidade esportiva, pois saberão e compreenderão melhor o significado de cada um dos itens que compõem uma categoria. Apesar de toda a tecnologia para o melhor entendimento dos Jogos Desportivos Coletivos, caberá ao responsável pela criação do banco de dados ser um profundo conhecedor da modalidade esportiva em específico e não um exímio conhecedor de informática. Isto para assegurar a garantira da qualidade dos dados registrados, já que a tarefa de análise de jogo é dificultada pelo elevado número de elementos a se observar, pela variabilidade, imprevisibilidade e aleatoriedade de comportamentos e ações durante um jogo e pela multiplicidade de critérios assumidos na definição e identificação dos 
elementos focalizados na observação. Ressalta-se que, seja na pesquisa científica ou dentro do treinamento de uma equipe, a pessoa responsável pelo registro das ações de jogo deverá conhecer o significado das informações do banco de dados, para saber interpretá-las na construção do saber científico e/ou na avaliação e elaboração de planos táticos para a equipe. Assim, a observação e o registro para criação do banco de dados requerem rigor e honestidade intelectual para com a coleta, paciência e constância com as inúmeras e múltiplas ocorrências durante o confronto de duas equipes e conhecimento da tecnologia e do jogo a ser avaliado (ANGUERA, 2000; GARGANTA, 1999, 2001; LIEBERMANN et al., 2002; ZAMBERLAM, 2005).

Além desses softwares, que permitem a calibração da imagem, há os que executam cálculos, tratamento estatístico dos dados, para averiguar, por exemplo, a existência de associações entre os itens de cada uma das categorias, tais como o SDIS-GSEQ e o DATA MINING (BAKEMAN; KERA, 1995; SAMPAIO, 1999; AMARAL; GARGANTA, 2005). Já nos softwares de calibração de imagem, tal procedimento para averiguar as associações entre as variáveis não existe, sendo possível o uso da estatística descritiva em cada uma das categorias e a opção de importação dos dados para um programa estatístico (MATIAS et al., 2005; ZAMBERLAM, 2005).

Um meio para a coleta da análise de jogo ser feita de modo rápido, sem a necessidade de uma pessoa ter de combinar a compreensão de uma das modalidades esportivas com conhecimento de hardware e softwares, é o uso de programas de computador, Skout (Figuras 2, 3 e 4) e Amisco, que permitem o rastreamento automático das trajetórias percorridas e das velocidades dos jogadores em tempo real por meio de utilização mínima de 4, 8, 10 ou 12 câmeras fixas. O problema se encontra nas regiões sobrepostas, pois pode não ser possível separar e identificar três ou mais jogadores que estejam extremamente próximos uns dos outros. Nesses casos de oclusão entre três ou mais jogadores, excepcionalmente, é necessária a intervenção de um indivíduo com compreensão da modalidade e da tecnologia em questão (BARROS et al., 1999; CUNHA; BINOTTO; BARROS, 2001; GARGANTA, 2001; FIGUEROA et al., 2003; ORTEGA et al.,
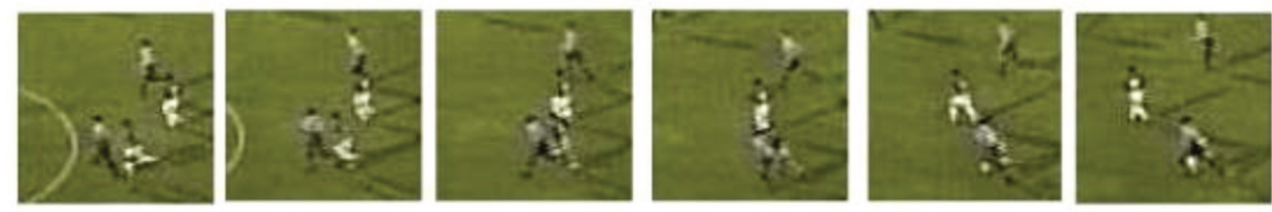

Figura 2 - Software de rastreamento automático, Skot. Sequência de imagens de um jogo.(BARROS et al., 1999; CUNHA; BINOTTO; BARROS, 2001; FIGUEROA et al., 2003).
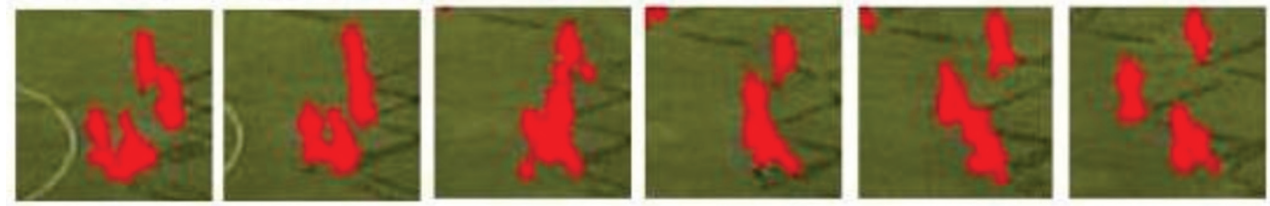

Figura 3 - Software de rastreamento automático, Skot. Obtenção automática das imagens de um jogo.(BARROS et al., 1999; CUNHA; BINOTTO; BARROS, 2001; FIGUEROA et al., 2003). 


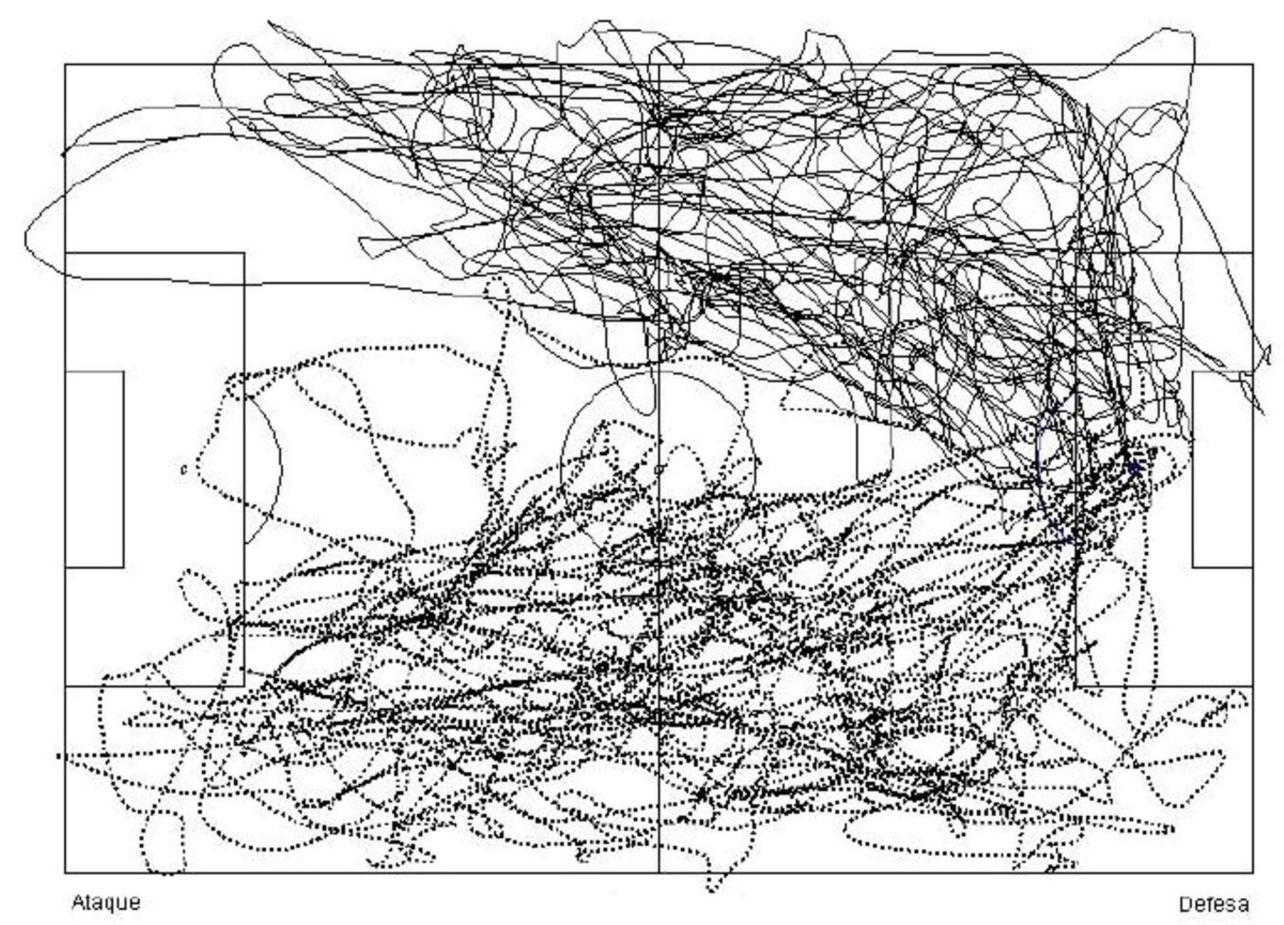

Figura 4 - Software de rastreamento automático, Skot. Aplicação de filtro, visualização da movimentação do lateral direito (—) e lateral esquerdo (......) (BARROS et al., 1999; CUNHA; BINOTTO; BARROS, 2001; FIGUEROA et al., 2003).

Devido ao elevado custo dos softwares de análise de jogo, tem sido adaptados outros que não possuem especificamente o objetivo de ser uma ferramenta para auxiliar na compreensão das modalidades esportivas, tal como o The Observer e o Transana. Ambos os softwares permitem a criação de categorias e itens, sendo que os registros desses itens durante o jogo são acoplados à imagem real gravada em vídeo e podem ser filtrados. Além disto, o The Obsever permite a realização de testes estatísticos, mas nenhum dos dois programas permite a construção geométrica no campo de jogo do respectivo esporte. Estes softwares demonstraram serem perfeitamente adaptáveis para realização da análise de jogo das modalidades esportivas (VILANI; ABURACHID; GRECO, 2006; TAYLOR et al., 2008; VILLASEÑOR; ANGUERA, 2008).

\section{Análise de jogo: voleibol}

Entre as modalidades investigadas via análise de jogo se encontra o voleibol, do ponto de vista científico e no dia a dia das comissões técnicas com os seus jogadores (GARGANTA, 2001; PEREIRA; MESQUITA, 2004; ZAMBERLAN, 2005). O voleibol é um jogo de oposição-colaboração (RIERA, 1989 apud MESQUITA, 1996), no qual a ação de uma equipe se desenvolve em um espaço separado daquele do adversário. Essa condição promove uma alternância sistemática entre o ataque e defesa (PAULA, 2000). Desse modo, segundo Mesquita (2005), a modalidade se diferencia das demais modalidades coletivas (futebol, futsal, basketball, handebol, póloaquático, ente outras), uma vez que no voleibol a equipe atua com a posse da bola na defesa, já nas outras modalidades a atuação é feita com a posse da bola no ataque e 
sem a posse da bola na defesa. Além dessas diferenças, encontra-se a lógica do jogo que é constituída por meio da ordem sequencial dos seus seis fundamentos (MESQUITA, 2005): saque, passe, ataque, levantamento, bloqueio e defesa.

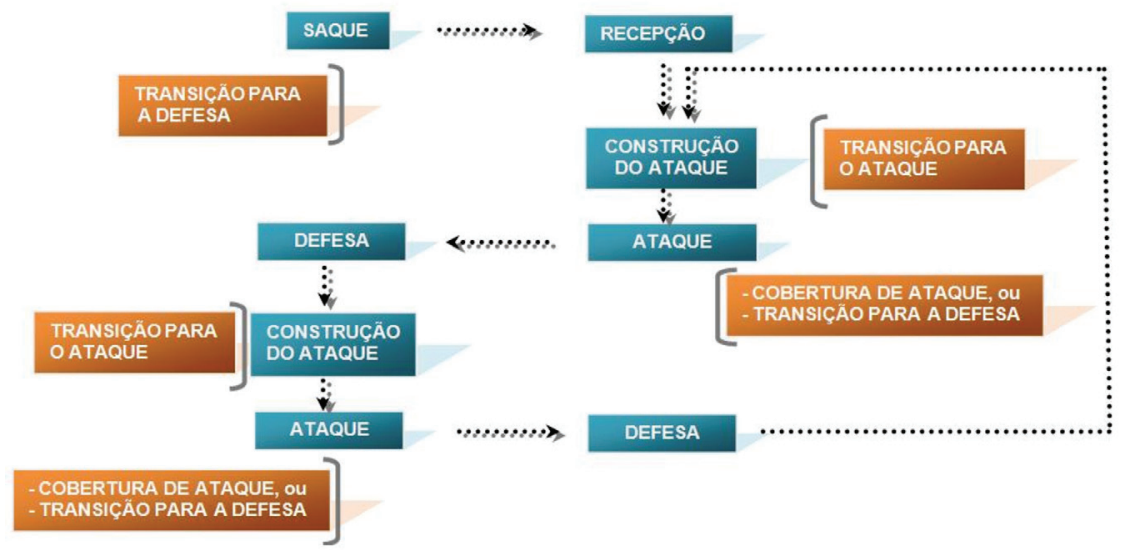

Figura 5 - Sequência dos momentos de jogo no voleibol. Beal (1989) e Moutinho (1995).

De acordo com Monge (2003), Mesquita (2005) e Palao, Santos e Ureña (2005), a fase de ataque no voleibol (ataque a partir da recepção do saque) e a fase de defesa (início da sequência de ataque a partir da defesa do ataque adversário) são denominadas, tradicionalmente, na escola americana, de side out e transition, na escola européia de complexo 1 (K1) e complexo 2 (K2) e no Brasil de ataque e de contra-ataque, respectivamente. Monge (2003), em sua proposta, Figura 6, amplia os complexos de jogo para complexo zero (K0), complexo um (K1), complexo dois (K2), complexo três (K3) e complexo quatro (K4). A equipe, ao executar o saque, poderá participar dos complexos: K0, K2, K3 e K4; a equipe, ao efetuar a recepção do saque, poderá participar dos complexos: K1, K3 e K4.

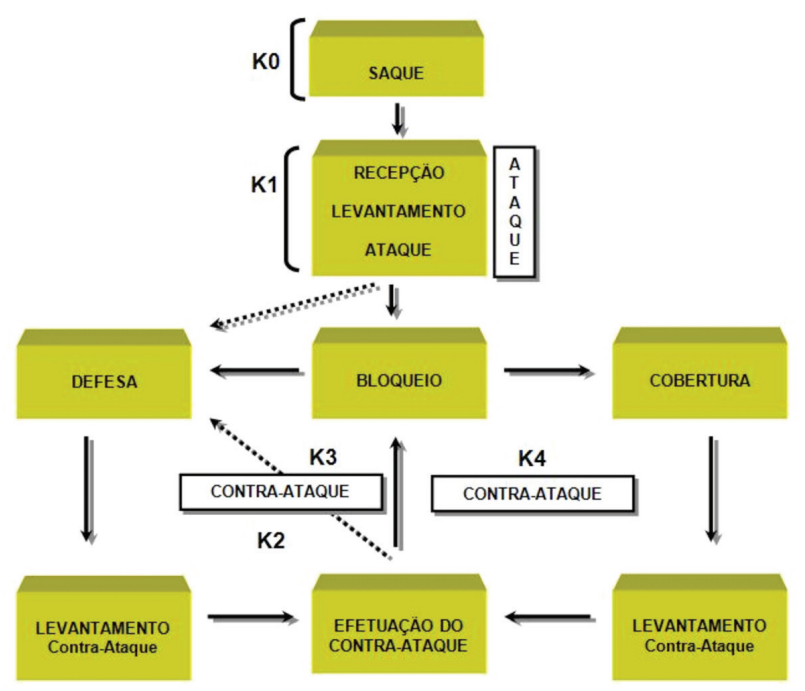

Figura 6 - Proposta do ciclo cronológico de uma jogada de voleibol. (MONGE, 2003). 
A proposta de Monge (2003) define os seguintes momentos do jogo

- K0: toda movimentação que realiza a equipe em posse do saque;

- K1: a recepção do saque em conjunto com o levantamento e a defesa (ataque);

- K2: toda a sequência com início na defesa do ataque adversário, após K1, seguida pelo levantamento e o ataque (contra-ataque);

- K3: após uma equipe ter efetuado a recepção do saque e o ataque no complexo $\mathrm{K} 1$, ela estará no complexo K3 se estiver novamente com a posse da bola, por meio da defesa do ataque adversário, que permitirá então o levantamento e o ataque; após uma equipe ter efetuado o saque e o ataque no complexo K2, ela estará no complexo K3 se estiver novamente com a posse da bola, por meio da defesa do ataque adversário, que permitirá então o levantamento e o ataque;

- K4: toda sequência realizada no instante da recuperação do ataque que foi bloqueado pelo adversário (cobertura de ataque).

No caso da previsibilidade de jogo, a ausência da invasão (contato físico) e o fato da partida não estar condicionada ao tempo disponível de jogo, geram maior previsibilidade ao voleibol em relação a outras modalidades esportivas coletivas. A imprevisibilidade é maior, por exemplo, no futebol, já que nele existe a invasão e a indeterminação do momento decisivo do jogo. Apesar da previsibilidade existente no jogo de voleibol, o atleta deverá apresentar uma elevada capacidade adaptativa, será preciso ser apto a produzir ações inesperadas pelo adversário. Em um ambiente (jogo) em que as condições táticas individuais, de grupo e coletivas inerentes às duas equipes que se confrontam são relativamente previsíveis, é necessário incluir a imprevisibilidade nas ações de jogo (MESQUITA, 1996, 2005).

\section{Análise de jogo: evolução tática do voleibol}

Ugrinowitsch e Uehara (2006), ao abordarem a evolução tática do voleibol, expõem que os Jogos Olímpicos são marcos de transformações na modalidade. As novidades são fruto da competição masculina, em seguida as equipes femininas buscam a implantação destas alterações táticas em seus planos de jogo (RIZOLA, 2003; UGRINOWITSCH; UEHARA, 2006). No Quadro 1, observa-se uma referência temporal do voleibol masculino nos Jogos Olímpicos, com o país campeão e as novidades táticas presentes na competição que influenciaram o voleibol mundial.

\begin{tabular}{|l|l|l|}
\hline Competição & Campeão & Modificações \\
\hline $\begin{array}{l}\text { Jogos Olímpicos } \\
\text { de 1964 emTóquio } \\
\text { e de 1968 na } \\
\text { cidade do México }\end{array}$ & União Soviética & $\begin{array}{l}\text { ・os jogadores eram mais altos e mais fortes que } \\
\text { seus adversários, desse modo o jogo baseava-se em } \\
\text { ataques e bloqueios muito fortes; } \\
\text { - países asiáticos, apesar do melhor domínio } \\
\text { técnico, não tinham condições de enfrentar } \\
\text { adversários com estilo de jogo baseado em ataques } \\
\text { e bloqueios fortes; }\end{array}$ \\
\hline & & \multicolumn{1}{c}{ (continua) } \\
\hline
\end{tabular}




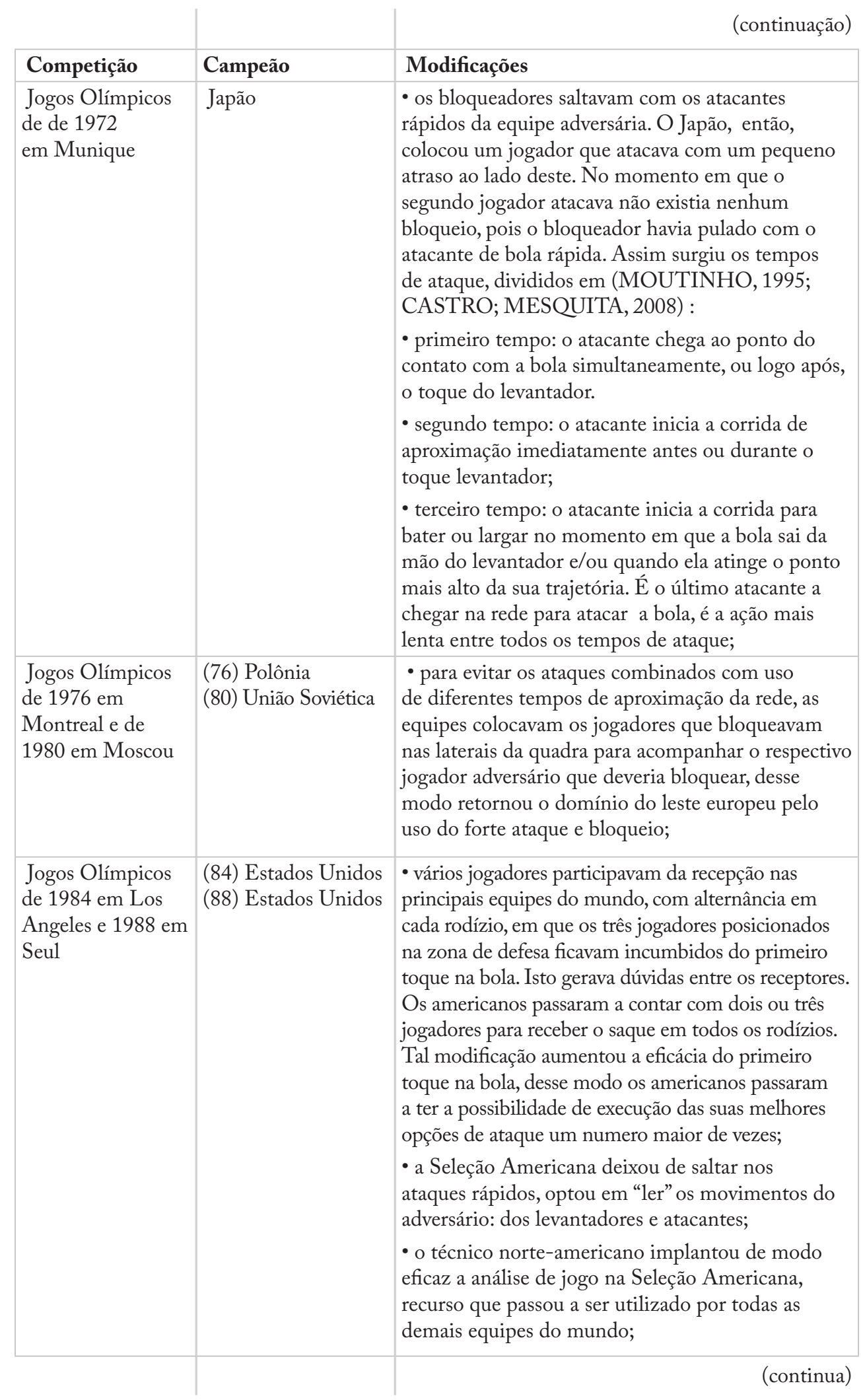




\begin{tabular}{|c|c|c|}
\hline & & (continuação) \\
\hline Competição & Campeão & Modificações \\
\hline $\begin{array}{l}\text { Entre os Jogos } \\
\text { Olímpicos de } 1988 \\
\text { em Seul } \\
\text { e } 1992 \mathrm{em} \\
\text { Barcelona }\end{array}$ & & $\begin{array}{l}\text { • o saque passou a ser feito em suspensão ("viagem } \\
\text { ao fundo do mar"), assim, era possível atacar a bola } \\
\text { com força, apesar da longa distância, pois a ação } \\
\text { se executava sobre o bordo superior da rede. Desse } \\
\text { modo, era necessário inserir mais um jogador na } \\
\text { recepção, dois ou três não eram suficientes para } \\
\text { garantir o levantamento da própria equipe; }\end{array}$ \\
\hline $\begin{array}{l}\text { Jogos } \\
\text { Olímpicos } \\
\text { de } 1992 \\
\text { em Barcelona }\end{array}$ & Brasil & $\begin{array}{l}\text { - os atacantes brasileiros ao atacar não ficavam } \\
\text { fixos em suas posições, os centrais, o oposto e os } \\
\text { ponteiros alteravam suas posições; } \\
\text { • a quebra de um estilo conservador de } \\
\text { levantamento, que enfatizava a precisão, facilitava } \\
\text { a “leitura" do bloqueio adversário. Por meio do } \\
\text { levantador Maurício, a Seleção Brasileira executava } \\
\text { inúmeras variações ofensivas. Utilizava ataques de } \\
\text { todas as seis posições, com prioridade para o jogo } \\
\text { sem cruzamentos, para aumentar a distância entre } \\
\text { os bloqueadores e para dar mais velocidade ao jogo } \\
\text { o levantador procurava atuar o maior número de } \\
\text { vezes em suspensão; }\end{array}$ \\
\hline $\begin{array}{l}\text { Jogos Olímpicos } \\
\text { de } 2000 \text { em Sidney }\end{array}$ & Iugoslávia & $\begin{array}{l}\text { - aumento da utilização do bloqueio triplo contra } \\
\text { ataques de terceiro tempo; }\end{array}$ \\
\hline $\begin{array}{l}\text { Jogos Olímpicos } \\
\text { de } 2004 \text { em Atenas }\end{array}$ & Brasil & $\begin{array}{l}\text { - a utilização de ataques rápidos com jogadores } \\
\text { oriundos da zona de defesa, na situação de side-out } \\
\text { e transition. }\end{array}$ \\
\hline
\end{tabular}

Quadro 1 - Evolução tática do voleibol. Adaptado de Baacke (1978), Palao et al. (2004) e Ugrinowitsch e Uehara (2005).

Os estudos de Matias, Lima e Greco (2006a, 2006b), a respeito da distribuição de jogo do Brasil nas finais da competição de voleibol masculino nas Olimpíadas de 1984 (Estados Unidos 3x1 Brasil) e 2004 (Brasil 3x1 Itália), concluíram a maior ocorrência de situações favoráveis aos atacantes. O levantador brasileiro de 2004 conseguiu criar contextos em que os atacantes se confrontaram com um bloqueador (1x1) e instantes sem a presença de bloqueio (1x0). Além disso, em relação ao levantador de 1984, as ações de 2004 ocorreram em suspensão, com o levantador dando mais velocidade as suas ações de levantamento. Mesmo com recepções e defesas deficitárias, houve levantamentos rápidos e precisos, bem como um número maior de atacantes mobilizados na distribuição de jogo.

\section{Considerações finais: análise de jogo do voleibol atual}

Nos estudos de análise de jogo a respeito do voleibol atual, o ataque é uma ação decisiva para a obtenção do ponto, da vitória na partida e da conquista do campeonato (RESENDE, 1995; MOUTINHO; MARQUES; MAIA, 2003; PEREIRA; 
MESQUITA, 2004; RAMOS et al., 2004; PALAO; SANTOS; URENÃ, 2005). Dentro de tal importância, o levantador emerge como jogador determinante para o rendimento da equipe quando a sua atuação preenche as condições de distribuição, que se interagem (Figura 7), descritas por Moutinho, Marques e Maia (2003):

- as condições de levantamento (qualidade de recepção e/ou defesa) não estão fortemente relacionadas às condições de finalização [relação atacante/bloqueador(es)];

- as condições de finalização [relação atacante/bloqueador(es)] estão fortemente relacionadas com o efeito da finalização (resultado da ação do atacante: ponto, erro, defesa do adversário, bloqueio e recuperação da própria equipe);

- condições de levantamento (qualidade da recepção e/ou defesa) não estão fortemente relacionadas com o efeito da finalização.

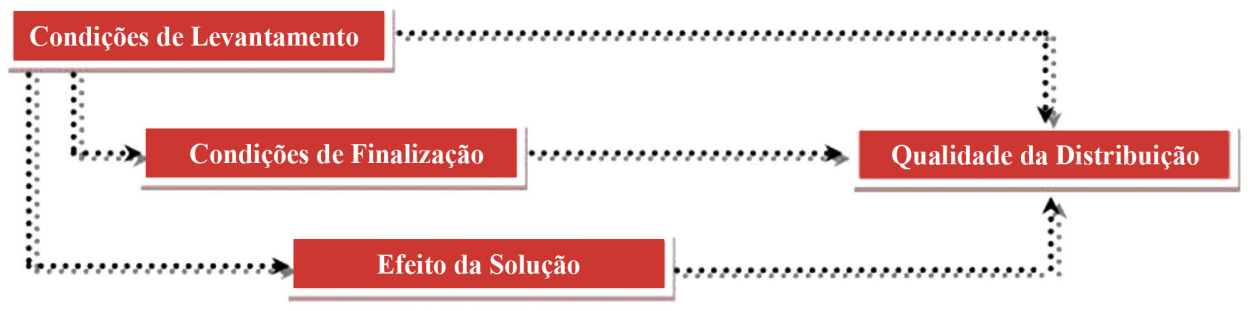

Figura 7 - Relação das variáveis de distribuição de jogo no voleibol. (MOUTINHO; MARQUES; MAIA, 2003).

De acordo com Moutinho, Marques e Maia (2003), a variável condição de levantamento é independente da ação do levantador, mas influencia as condições de finalização e a variável efeito da finalização. A variável condição de finalização, embora influenciada pela qualidade da condição de levantamento, é dependente da ação do levantador e influencia a variável efeito da finalização. A variável efeito da finalização é paralelamente dependente e independente da ação do levantador, e é influenciada pelas variáveis condição de distribuição e criação de oportunidades. A qualidade de distribuição é o resultado da interação das variáveis: condição de distribuição, condição de finalização e efeito da solução.

Tanto os levantadores, ao tomarem suas decisões táticas, quanto os treinadores e os pesquisadores, ao analisarem essas decisões no contexto de jogo, estarão sempre a avaliar a atuação tática coletiva de seis times em quadra. Isto, pois, cada rodízio oferece uma nova formação de jogadores na zona de ataque e de defesa. Tal configuração exige um domínio cognitivo desses jogadores, que deverão saber averiguar o rendimento tático individual, de grupo e coletivo em cada um dos diferentes posicionamentos rotatórios da sua equipe e esses combinados com as seis diferentes formações táticas do adversário. Esta combinação é perturbada por uma inconstância em situações de contra-ataque (transition), ocasionada por situações imprevistas de qualidade de passe para a construção ofensiva, que consequentemente limita a distribuição do levantador: terá um número pequeno de atacantes para movimentar taticamente; menor número de posições que poderão receber o levantamento e dificuldade de imprimir velocidade e precisão nestes. 
Desse modo, haverá dificuldade em sobrecarregar a "leitura" dos sinais do bloqueio adversário. Já no ataque (side-out), a construção é feita com uma qualidade superior de primeiro toque, mas se exige, então, que o levantador quebre a previsibilidade ou a expectativa do bloqueio adversário de ter antecipadamente reconhecido o produto de sua ação: determinada velocidade em uma zona específica da quadra para um jogador executar seu ataque (MESQUITA, 1996, 2005; MINOWA; YOSHIDA, 2001; MOUTINHO; MARQUES; MAIA, 2003; MESQUITA; PEREIRA, 2004; RAMOS et al., 2004; PALAO; SANTOS; URENÃ, 2004).

Garganta e Oliveira (1996) sustentam que não se diferencia estratégia e tática, as duas possuem a mesma estrutura cognitiva e o mesmo foco situacional que se funde no ato motor do atleta. Ressaltar isto é necessário devido as classificações que descrevem estratégia como preparação das tomadas decisórias antes do jogo, decisões elaboradas principalmente por parte do técnico, e tática como decisões no momento do jogo. Cada jogador deve ser um estrategista capacitado para integrar as suas soluções táticas individuais, na perspectiva de jogo e da sua equipe e vice-versa.

\title{
Agradecimentos
}

Agradecimento à Coordenação de Aperfeiçoamento de Pessoal de Nível Superior (Capes) e ao Conselho Nacional de Desenvolvimento Científico e Tecnológico $(\mathrm{CNPq})$ pelo apoio para o desenvolvimento do presente estudo.

\section{Analysis of the game games team ball sports: the example of volleyball}

\begin{abstract}
Team Ball Sports, since 1930, are studied in the Science of Sports and the coach's committees for their own tools for the match analysis, to better understand the logic of the games. This article aims to present the application and the technological resources to match analysis. Furthermore, the analysis presents the game through sport Volleyball sport by changing tactics and its practice at a high level in sport today. In the game of volleyball is always six different times in court, combined with six different times of the opponent with combinations depending on the stage of the game, setting the importance of such an analysis of the volleyball game.
\end{abstract}

Key-words: Match Analysis - Team Ball Sports - Volleyball.

\section{Análisis de juego en juegos deportivos colectivos: el ejemplo del voleibol}

\section{Resumen \\ los Juegos Deportivos Colectivos, desde 1930, son estudiados en las Ciencias del Deporte y por las pro- pias comisiones técnicas por medio de instrumentos de análisis del juego, para una mayor comprensión de la lógica de los juegos. Este artículo busca presentar la aplicación y los recursos tecnológicos para el análisis del juego. Además, presenta el análisis de juego ejemplificado en la modalidad deportiva Volei- bol, mediante la evolución táctica y su práctica de alto nivel en el deporte actual. En el juego de Voleibol hay siempre seis diferentes times en la cancha, combinando con seis diferentes times del adversario, con combinaciones dependiendo de la etapa del juego, configurando de tal modo la importancia del análisis de juego en el Voleibol.}

Palabras claves: Análisis de juego - Juegos Deportivos Colectivos - Voleibol. 


\section{Referências}

AMARAL, R.; GARGANTA, J. A modelação do jogo em futsal. Análise sequencial do 1x1 no processo ofensivo. Revista Portuguesa de Ciências do Desporto, v.5, n.3, p. 298-310, 2005.

ANGUERA, M.T. Observación en deporte y conducta cinésico-motriz: aplicaciones. 1. ed. Barcelona: Publicacions de la Universitat de Barcelona, 2000.

ARAÚJO, D.; VOLOSSOVITCH, A. Fundamentos para o treino da tomada de decisão: uma aplicação ao handebol. In: ARAÚJO, D. (Ed.). O contexto da decisão, a aç̧ão táctica no desporto. 1.ed. Lisboa: Visão e Contextos, 2005. p.75-98.

BAACKE, M.B. História e atual situação do volleyball. In: BAACKE, M. B. et al. (Eds.). Manual do treinador da Confederação Brasileira de Voleibol. 1. ed. Rio de Janeiro: Palestra Edições, 1978. p.1.01-1.07.

BAACKE, M.B. MATSUDAIRA, Y. Análise de Jogo. In: BAACKE, M. B. et al(Eds.). Manual do treinador da Confederação Brasileira de Voleibol. 1. ed. Rio de Janeiro: Palestra Edições, 1978. p.12.01-12.15.

BAKEMAN, R.; QUERA, V. Analyzing interaction: sequential analysis with SDIS-GSEQ.1. ed. New York: Cambridge University Press, 1995.

BARROS, R.M.L. et al. Desenvolvimento e avaliação de um sistema de análise cinemática tridimensional de movimentos humanos. Revista Brasileira de Engenharia Médica, v.15, n.1/2, p.79-86, 1999.

BEAL, D. Basic team system and tactics. In: FÉDÉRATION INTERNATIONALE DE VOLLEYBALL (Ed.). Coaches manual I, 1. ed. Lausane: FIVB. 1989. p.333-356.

COLEMAN, J. Analisando os adversários e avaliando o desempenho da equipe. In: SHONDELL, D.; REYNAULD, C. (Eds.). A bíblia do treinador de voleibol, 1. ed. Porto Alegre: ArtMed, 2005. p.315-338.

CUNHA, S. A.; BINOTTO, R. B.; BARROS, R. M. C. Análise da variabilidade na medição de posicionamento tático no futebol. Revista Paulista de Educação Física, v.15, n. 2, p.111-116, 2001.

FIGUEROA, P. et al. Detecção automática da posição de jogadores de futebol usando processamento de imagens. In: X CONGRESSO BRASILEIRO DE BIOMECÂNICA. Anais..., v.1, n.1, p.189-193, 2003.

FRANKS, I.; McGARRY, T. The science of match analysis. In: REILLY, T. Science and soccer. 1. ed. London: Routledge. 1996. p.363-375.

GARGANTA, J. A análise do futebol. Percurso evolutivo e tendências In: TAVARES (Ed.). Estudos 2.1. ed. Porto: CEJD. 1999. p.14-40.

GARGANTA, J A análise da performance nos jogos desportivos. Revisão acerca da análise do jogo. Revista Portuguesa de Ciências do Desporto, v.1, n. 57, p. 57-64, 2001. 
GARGANTA, J.; OLIVEIRA, J. Estratégia e táctica nos jogos desportivos coletivos. In: OLIVEIRA, J.; TAVARES, F. (Eds.). Estratégia e táctica nos jogos desportivos coletivos. 1. ed. Porto: CED. 1996. p.7-24.

GRECO, P. J.; BENDA, N. R. Iniciação esportiva universal: da aprendizagem motora ao treinamento técnico, volume I. 1. ed. Belo Horizonte: Editora UFMG. 1998.

GRECO, P. J.; CHAGAS, H. M. Considerações teóricas da tática nos jogos desportivos coletivos. Revista Paulista de Educação Física, v. 6, p.47-58, jul/dez. 1992.

HUGHES, M. D.; BARTLLET, R. M. The use of performance indicators in performance analysis. Journal of Sports Sciences, Oxford, v. 20, n.10, p.739-754, 2002.

LERBACH, M. A.; LIMA, W. O. Formação das seleções básicas no voleibol brasileiro, 1. ed. Brasília: Publicações Indesp. Série Ciências do Esporte. 1998.

LIEBERMANN, D.G. et al. Advances in the application of information technology to sport performance. Journal of Sports Science, v. 20, n.10, p. 755-769, 2002.

MATIAS, C. J. A. S. et al. Análise da tomada de decisão no contexto de jogo através do software Simi Scout. Revista Perfil, v. 7, n. 8, p.105-105, 2005.

MATIAS, C. J. A. S.; LIMA, C. O.; GRECO, P. J. A evolução do sistema defensivo no voleibol: análise da seleção brasileira em duas finais Olímpicas - 1984 e 2004. Brasilian Journal of Physical Education and Sport, v. 20, n. 5, p. 484-484, 2006a

MATIAS, C. J. A. S.; LIMA, C. O.; GRECO, P. J. A evolução estratégico-tática da organização ofensiva executada pelo levantador em duas finais Olímpicas. Brasilian Journal of Physical Education and Sport, v. 20, n. 5, p. 484-484, 2006 b.

MESQUITA, I. Contributo para a estruturação das tarefas no treino em voleibol. In: OLIVEIRA, J.; TAVARES, F. (Eds.). Estratégia e táctica nos jogos desportivos coletivos. 1. ed. Porto: CED. 1996. p. 95-103.

MESQUITA, I. A contextualização do treino no voleibol: a contribuição do construtivismo. In: ARAÚJO, D. O contexto da decisão - acção táctica no desporto, 1. ed. Lisboa: Colecção Visão e Contextos das Ciências do Desporto. 2005. p. 355-378.

MINOWA, K.; YOSHIDA, T. A study on the setter in volleyball games. International Journal of Volleyball Research, v. 3, n. 1, p.70. 2001.

MONGE, A. M. Propuesta estructural del desarrollo del juego en Voleibol. In: MESQUITA, I.; MOUTINHO, C. A. S. S.; FARIA, R. (Eds.). Investigação em voleibol: estudos ibéricos, 1. ed. Porto: FCDEF-UP, 2003. p.142-149.

MORENO, F. M. A. Aplicación de un sistema observacional para el análisis del lanzamiento en balonmano en el Mundial de Francia 2001. Apunts: Educación Física y Deportes, n.71, p.100-109, 2003.

MORTENSEN, N. P. Development of a notational analysis system to evaluate setting performance in volleyball. 93f. 2007. (Doutorado em Ciências do Esporte) - Universidade de Brigham. 2007. 
MOUTINHO, C. A. S. S O ensino do voleibol: a estrutura funcional do voleibol. In: GRAÇA, A.; OLIVEIRA, J. (Eds.). O ensino dos jogos desportivos, 2. ed. Porto: Universidade do Porto, 1995. p.137-152.

MOUTINHO, C.; MARQUES, A.; MAIA, J. Estudo da estrutura interna das acções da distribuição em equipes de voleibol de alto nível de rendimento. In: MESQUITA, I.; MOUTINHO, C.; FARIA, R. (Eds.). Investigação em voleibol: estudos ibéricos, 1. ed. Porto: FCDEF-UP, 2003. p.107-129.

NETO, J. M. M. N. A importância dos indicadores estatísticos para a obtenção da vitória no Campeonato Mundial de Basquetebol adulto masculino 2006. Fitness \& Performance Journal, v. 6, n.1, p. 57-61, 2007.

ORTEGA, J. P. et al. Evolución en las herramientas para la observación en el futbol. Revista Portuguesa de Ciências do Desporto, v.7, n.1 (Suplemento), p.67-68. 2007.

PALAO,J.M.; SANTOS, J. A.; UREÑA, A. Effect of the setter's position on the block in volleyball. International Journal of Volleyball Research, v. 6, n. 1, p. 29-32, 2004.

PALAO, J. M.; SANTOS, J. A.; UREÑA, A. The effect of the setter's position on the spike in volleyball.Journal of Human Movement Studies, v. 48, n. 1, p. 25-40, 2005.

PAULA, A. F.P. Processo de validação de teste para avaliar a capacidade de decisão tática e o conhecimento declarativo no voleibol: situações de ataque de rede. 2000. 215f. (Mestrado em Educação Física: Treinamento Esportivo) - Escola de Educação Física, Fisioterapia e Terapia Ocupacional da Universidade Federal de Minas Gerais, Belo Horizonte, 2000.

PEREIRA, F.; MESQUITA, I. Estudo comparativo das aç̧ões de distribuição e efeito do ataque de equipes de voleibol feminino de nível competitivo distinto. Revista Portuguesa de Ciências do Desporto, v. 4, n. 2 (Suplemento), p.206-206, 2004.

PONCE, F. M. J.; ORTEGA, P. J. Propuesta de un método para cuantificar el comportamiento táctico de los equipos de fútbol. Apunts: Educación Física y Deportes, n. 71, p. 92-99. 2003.

QUEIROGA, M. A. O Conhecimento táctico-estratégico do distribuidor de alto nível: um estudo com os distribuidores das seleções brasileiras de voleibol feminino e masculino. 2005. 180f. (Mestrado em Treino de Alto Rendimento) - Faculdade de Ciências do Desporto e de Educação Física da Universidade do Porto, Porto, 2005.

RAMOS, P. K. H. M. et al. Estrutura interna das ações de levantamento das equipes finalistas da superliga masculina de voleibol. Revista Brasileira de Ciência e Movimento, v.12, n. 4, p. 33-37, 2004.

RESENDE, B. Levantador, uma simples questão de personalidade. Revista Vôlei Técnico, v. 1, n. 3, p. 5-11, 1995.

RIZOLA, A. N. Uma proposta de preparação para equipes jovens de voleibol feminino. 2003. 135f. (Mestrado em Educação Física: Ciência do Desporto) - Faculdade de Educação Física da Unicamp, Campinas, 2003. 
RUANO, M. A. G.; CALVO, A. L. Análisis discriminante de lãs estadísticas de juego entre bases, aleros y pivots em baloncesto masculino. Apunts: Educación Física y Deportes, n. 87, p. 86-92, 2007.

SAMPAIO, A. J. Análise do jogo em basquetebol: da pré-história ao data mining. Lecturas Educación Física y Deportes, v. 4, n.15, p. 01-04, 1999.

SZWARC, A. The efficiency model of soccer player's actions in cooperation with other tem players at the Fifa World Cup. Humam Movement, Wrocław, v. 9, n.1, p. 56-61. 2008.

TAYLOR, J. et al. The influence of match location, quality of opposition, and match status on technical performance in professional association football. Journal of Sports Sciences, v. 26, n. 9, p. 850-895, 2008.

UGRINOWITSCH, C.; UEHARA, P. Modalidades esportivas coletivas: o voleibol. In: DE ROSE, J. D. (Ed.). Modalidades esportivas coletivas, 1. ed. Rio de Janeiro: Editora Guanabara, 2006. p.166-179.

VILANI, L. H. P.; ABURACHID, L. M. C.; GRECO, P. J. Proposta metodológica de análise de vídeo por meio de software livre no tênis de mesa adaptado. Brazilian Journal of Physical Education and Sport, v. 20, n. 5, p. 490, 2006.

VILHENA, M. S. Processo de ensino-aprendizagem-treinamento no futsal: influência no conhecimento tático-processual. 2007. 208f. (Mestrado em Educação Física: Treinamento Esportivo) - Escola de Educação Física, Fisioterapia e Terapia Ocupacional da Universidade Federal de Minas Gerais. 2007.

VILLASEÑOR, Á. B.; ANGUERA, T. M. Inter-and intra-observer reliability with data recorded through 'The Observer' and 'Match Vision Studio'. In: SPINK, A.J. et al. Proceeding of measuring behavior. 1. ed. Maastricht: The Netherlands. 2008. p.337.

WNOROWSKI, K. Technical and tactical control criteria and coach's evaluation of volleyball player. MedSportPress, v.13, n.1, p. 82-85, 2007.

ZAMBERLAM, A. O. et al. A inteligência artificial entrando na quadra de vôlei: scout inteligente. Revista Hífen, v. 29, n. 55/56, p.103-110, 2005.

Recebido em: 29/09/2009

Revisado em: 02/11/2009

Aprovado em: 23/11/2009

Endereço para correspondência

Cristino Julio Alves da Silva Matias

Universidade Federal de Minas Gerais

Laboratório de Psicologia do Esporte (Grupo de Estudos de Cognição e Ação)

Avenida Presidente Carlos Luz, 4.664 - Pampulha,

CEP.: $31.310-250$

Belo Horizonte - Minas Gerais - Brasil

E-mail:crismatias@gmail.com 